\title{
Citrobacter koseri Bacterial Keratitis
}

\author{
de Souza RL*, da Costa AX, Salgado e CLM and Formentin L \\ Department of Ophthalmology Hospital Santo Amaro, Brazil
}

*Corresponding author: Rafael Lopes de Souza, Department of Ophthalmology

\section{Case Report \\ Volume 1 Issue 2}

Received Date: July 25, 2016

Published Date: August 01, 2016

Hospital Santo Amaro, Brazil, Tel: +55(13) 3389-1515; Email: lopesrafaels@hotmail.com

\section{Introduction}

Citrobacter koseri is a rare bacterium in eye infections, responsible for less than $1 \%$ of ophthalmological infectious diseases [1]. Studies reporting the incidence of eye diseases caused by Citrobacter $s p$ are still limited. We report the outcomes of this rare case of a Citrobacter koseri keratitis, reporting clinical course, response to antibiotics, differential diagnosis and developments.

\section{Case Report}

An 80-year-old male patient, retired, residing in the city of Guarujá - São Paulo in Brazil, came to the emergency room complaining about intense pain, blurred vision and redness in the right eye (OD) for about five days, associated with purulent discharge and right temporal headache. He could not recall any ocular trauma and he was not a contact lens wearer. He referred past medical history of controlled hypertension and leptospirosis (30 years ago), and past ocular history of glaucoma and amaurosis in the left eye (OS) due to a supposed ocular infection 20 years ago. The ophthalmological examination revealed visual acuity of hand movements in the OD and no light perception in the OS. Biomicroscopy of the OD showed eyelids with mild edema, normal distribution of eyelashes, bulbar and tarsal conjunctiva with intense hyperemia, purulent discharge, cornea presenting central ulcerated lesion measuring $4 \times 5 \mathrm{~mm}$, with stromal infiltrate, hypopyon grade II, hyphema grade I (Figure 1). The OE showed a quiet eye with corneal leucoma and neovascularization. Intraocular pressure was increased in both eyes and Fundoscopy was impossible to be done. Based on the history of the present illness, clinical signs and symptoms, it was suggested the etiological hypothesis of infectious keratitis. Samples were collected for culture through corneal scrapping with Kimura spatula, and it was started home use of moxifloxacin 5\% eye drops hourly until acquisition of fortified eye drops, acyclovir 2g/day, doxicyclin $200 \mathrm{mg} /$ day and therapeutic contact lens.

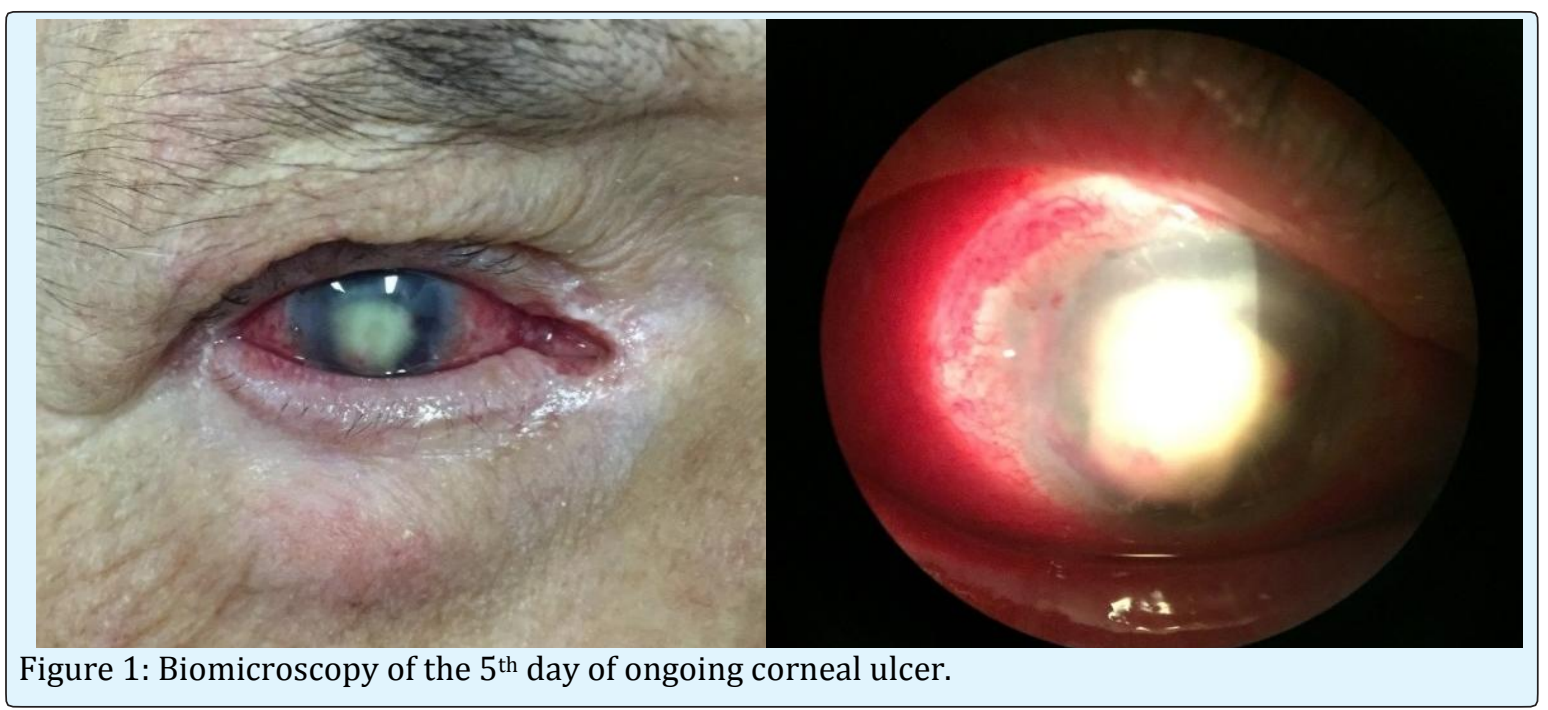




\section{Open Access Journal of Ophthalmology}

\section{Evolution}

The patient showed unsatisfactory development, with worsening of the ulcer and the pain on the fifth day, increased hypopyon and suspected endophthalmitis. Ultrasound examination was not available at that moment. He was than hospitalized for monitoring and intravenous treatment was initiated with ceftriaxone and vancomycin. Simultaneously the use of antibiotics via fortified eye drops was started with ceftazidime $50 \mathrm{mg} / \mathrm{mL}$ and vancomycin $25 \mathrm{mg} / \mathrm{mL}$ hourly. There was gradual and insidious improvement with the offered therapy. The result of the culture was positive for Citrobacter koseri (figure 2). No other infectious agents were identified in this case and after 25 days in hospital he was discharged with fully epithelialized cornea.

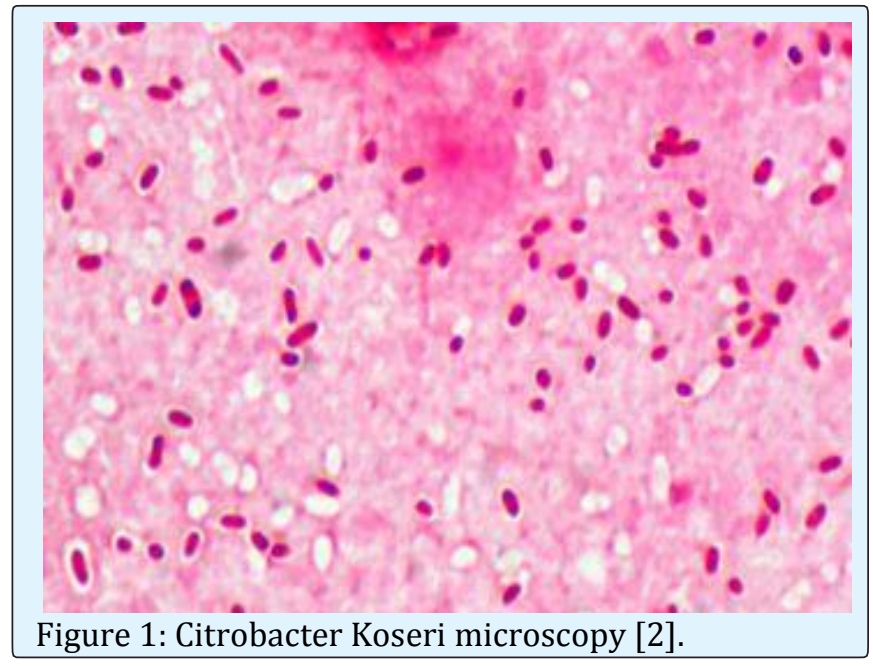

\section{Discussion}

Bacterial ulcers are usually associated with situations in which the corneal defense mechanisms are altered, such as eyelids dysfunctions, advanced age, poor hygiene and dry eye, what fits our patient's scenario.

The initial signs and symptoms of corneal ulcer depend on the aggressiveness of the bacteria, and often start with eye pain, hyperemia, ciliary injection and low visual acuity. In our case we found a suppurative corneal lesion, hypopyon, anterior chamber reaction, hyphema and intense pain.

Studies in Brazil in 1975 show that most part of normal micro flora of the eye consists of gram-positive bacteria and may be varied throughout life, depending on the age, weather and exposure. Eye injuries, surgeries, changes in the local immune system, and systemic factors can act as modifiers of the external eye microbiota. There are reports showing that in the elderly the incidence of Gram- negative bacteria is increased [3]. Citrobacter koseri is a facultative anaerobic, gram-negative bacillus belonging to the genus Citrobacter, within the family of Enterobacteriaceae. C. koseri is one of the most common species of the Citrobacter genus, and is commonly found in water, soil and as occasional colonizers of the gastrointestinal tract in humans [4]. There are few papers relating C. koserias the cause of ocular infection. Barsam et al. [5] described single case of panophthalmitisand phthisis secondary to $C$. koseri infection in a vitrectomized eye, and it has been isolated in a single case of infectious crystalline keratopathy [6]. It has been described as a cause of bacterialkeratitis [1,7,8] and corneal ulcer [9], but it was not found in the literature any cases of infectious keratitis or corneal ulcer caused by Citrobacter koseri in Brazil so far. Empirical treatment with topic broad spectrum antibiotic, based on the history and characteristics of the lesion was initiated soon after collection of samples for culture, in order not to delay the control of the infectious process, based on studies showing the incidence and characteristics of corneal infections $[1,10]$. The progression to endophthalmitis is feared in this case, since most case reports on ocular infections with Citrobacter koseri were described as endophthalmitis, characteristically insidious, progressive, painful and difficult to control, resulting in hospitalization, intravenous and intravitrealbroadspectrum antibiotics and fortified antibiotics eye drops $[4,7,11]$. The final visual acuity was of light perception in this eye. In most reported cases visual acuity after treatment was low or very low, especially after endophthalmitis cases, which are difficult to control $[4,7,11]$.

\section{References}

1. Antibiotic susceptibility: keratitis (2009) The Charles T Campbell Microbiology Lab.

2. Microbe Canvas Microbiology on the go. Dept. Medical Microbiology and Infectious diseases - Erasmus MC University Medical Center Rotterdam.

3. Hofling-Lima AL, Nishiwaki-Dantas $\mathrm{MC}$, Alves $\mathrm{MR}$ (2014) Doenças externas oculares e córnea, Conselho Brasileiro de Oftalmologia, 3 edição.

4. Kang MK, Chung EJ (2011) Late-Onset Citrobacter koseri Endophthalmitis with Suture Exposure after Secondary Intraocular Lens Implantation. Korean J Ophthalmol 25(4): 285-288. 


\section{Open Access Journal of Ophthalmology}

5. Barsam A, Heatley CJ, Herbert L (2006) Panophthalmitis secondary to infection with Citrobacter koseri. Eye 20(12): 1468-1470.

6. Khater TT, Jones DB, Wilhelmus KR (1997) Infectious crystalline keratopathy caused by gram-negative bacteria. Am J Ophthalmol 124(1): 19-23.

7. Ben Tovim T, Eylan E, Romano A, Stein R (1974) Gram-negative bacteria isolated from external eye infections. Infection 2(3): 162-165.

8. Keay L, Edwards K, Naduvilath T, Taylor HR, Snibson GR, et al. (2006) Microbial keratitis predisposing factors and morbidity. Ophthalmology 113(1): 109116.
9. Goold LA, Warrier SK, Wittles NK, Nathan F (2010) Microbial Keratitis Secondary to Infection With Citrobacter koseri. Cornea 29(4): 479.

10. Comarella JD, Saraiva PGC, Saraiva FP (2015) Úlcera de córnea: estudo retrospectivo de casos atendidos no Hospital das Clínicas da Universidade Federal do Espírito Santo, Rev Bras Oftalmo 74 (2): 76-80.

11. Schirmbeck T, Romão E, Rodrigues MLV, Figueiredo JFC (2000) Endoftalmite: uma análise de 58 casos. Arq Bras Oftalmol 63(1): 39-44. 